\title{
A Knowledge Elicitation Study for a Speech Enabled GIS to Handle Vagueness in Communication
}

\author{
Hongmei Wang \\ Northern Kentucky University, Department of Computer Science, Nunn Drive, \\ Highland Heights, KY 41099, USA \\ wangh1@nku.edu
}

\begin{abstract}
One of challenges toward development of usable speech enabled Geographical Information Systems (GIS) is how to handle vagueness that naturally exist in human-GIS communication. The meaning of some spatial concepts are not only fuzzy, but also context dependent. To enable the GIS to handle the vagueness problem, in particular, the context-dependency subproblem, we propose to design a collaborative speech enabled GIS, which can emulate a human GIS operator's role and handle the vagueness problem in communication through collaborative dialogues. To emulate a human GIS operator's role, the GIS must have knowledge corresponding to a human GIS operator's knowledge involved in handling the vagueness problem. This paper describes a knowledge elicitation study that we conducted to elicit human GIS operators' knowledge about how to handle the vagueness problem through collaborative dialogues. A speech enabled GIS, Dave_G, incorporates part of the study results. This system is able to handle the vagueness problem through various collaborative dialogues.
\end{abstract}

Keywords: GIS, Knowledge elicitation study, Vagueness problems, HumanGIS Communication, Collaborative dialogue strategies.

\section{Introduction}

Geographic Information Systems (GIS) are computer systems for capturing, storing, querying, analyzing, and displaying geographically referenced data [1], such as map layers of various spatial features (e. g. land parcels, roads, lakes, cities etc.). They have been broadly applied in various fields that use spatial data since the 1960s, for instance, natural resource management and assessment, criminal incident analysis, crisis management, automobile GPS, web-based map systems, etc.

To improve the system usability and support broader use of the system, the GIS community has spent much effort on designing transparent interfaces. One line of the efforts is to develop natural interfaces, e. g. speech and gesture enabled interfaces, to GIS [2-6]. There have been some experimental natural interfaces for geographic information use, such as "Put-that-There" [7], CUBISON [8], QuickSet [9-11], Sketch and Talk [12], iMap [13], and Dave_G [14].

Most of the existing experimental systems use speech as one of interaction modalities in communication with the user. To develop a usable sppech enabled GIS, one of 
the challenges that must be addressed is how to semantically interpret a speech request involving spatial concepts. The user's natural language requests can be incomplete, ambiguous, vague, and inconsistent [15-18]. The meaning of a vague linguist term representing a spatial concept is fuzzy, that is, its meaning does not have a clear boundary. Its meaning is also context dependent, that is, its meaning is different in different contexts. This study focuses on handling the vagueness problem in human-GIS natural language communication, in particular, the context-dependency sub-problem.

Human communicators can usually successfully communicate vague spatial concepts with each other through collaborative dialogues. For example, in an Emergency Operation Center for the hurricane crisis management in Florida, a crisis manager who does not know to operate GIS can collaborate with an expert GIS operator and can still get desired spatial information from the GIS although their natural language communication may involve vagueness. Success in collaborative human-human communication drives us to design a speech enabled GIS which can handle the vagueness problem by emulating a human GIS operator's role. The goal of this study is to collect human knowledge about how human communicators, in particular, human expert GIS operators, understand the meaning of a vague spatial concept in different contexts and reduce vagueness in communication through collaborative dialogues.

Knowledge elicitation is the process of collecting information that is thought to be relevant to desired knowledge from a human resource of knowledge [19]. There are various types of knowledge elicitation techniques [20-23]. The observations and interviews are often used for early stage of system design, such as, conceptualizing the problem domain. They are direct methods of watching experts and talking to them. In this study, we took these two techniques to collect human communicators' knowledge involved in handling vagueness in communication. This paper describes design, the data collection process, and preliminary findings of the knowledge elicitation study.

\section{Research Design}

Our research questions in the knowledge elicitation study are:

- 1) How do human communicators understand the meaning of a vague spatial concept in communication?

- 2) What kinds of collaborative dialogue strategies can be used by human communicators to reduce vagueness in communication of spatial concepts?

- 3) How does the human GIS operator reason when the user speaker's request involves a vague spatial concept?

The first knowledge elicitation technique that we planned to use is participant observation. We planned to invite pairs of GIS experts and non-expert GIS users to work together on a set of tasks (see Table 1) that involve communication of a vague spatial concept, near, and use of GIS commands. Through observing their collaboration process, we expected to answer the research question 2 and observe the communication between pairs of human communicators, in particular, collaborative dialogue strategies used to reduce vagueness in communication. 
The eight tasks are about getting a map near a reference location. The maps are required to fit for different contexts (Table 1). They have some contextual factors in common, such as the goal, time frequency/period and bigger spatial contexts, also have different contextual factors, such as transportation mode and reference locations.

Table 1. Eight Tasks in Participant Observation

\begin{tabular}{|c|c|c|c|c|}
\hline \multirow[t]{2}{*}{ Task No. } & \multirow[t]{2}{*}{ Task Content } & \multirow{2}{*}{$\begin{array}{l}\text { Common } \\
\text { Contextual } \\
\text { Information }\end{array}$} & \multicolumn{2}{|c|}{ Different Contextual Information } \\
\hline & & & $\begin{array}{l}\text { Transportation } \\
\text { mode }\end{array}$ & $\begin{array}{l}\text { Reference } \\
\text { location }\end{array}$ \\
\hline 1 & $\begin{array}{l}\text { Show a map } \\
\text { showing grocery }\end{array}$ & $\begin{array}{l}\text { Goal: food } \\
\text { shopping; }\end{array}$ & By driving a car & Apartment A \\
\hline 2 & $\begin{array}{l}\text { stores near a } \\
\text { home location. }\end{array}$ & $\begin{array}{l}\text { Time: Weekly; } \\
\text { Space: In a big }\end{array}$ & by walk & Apartment A \\
\hline 3 & & $\begin{array}{l}\text { city like New } \\
\text { York }\end{array}$ & By driving a car & Apartment B \\
\hline 4 & & & by walk & Apartment B \\
\hline 5 & $\begin{array}{l}\text { Show a map } \\
\text { showing }\end{array}$ & $\begin{array}{l}\text { Goal: Vacation; } \\
\text { Time: two day }\end{array}$ & By driving a car & City A \\
\hline 6 & near a home city. & weekend & By air & City A \\
\hline 7 & & & By driving a car & City B \\
\hline 8 & & & By air & City B \\
\hline
\end{tabular}

Near is a typical example used to illustrate the vagueness problem in communication of spatial concepts [15, 24-27]. We expected that using this concept in the tasks would lead to vagueness in communications between each pair of participants. We hoped that the vagueness problem would further stimulate the participants to use collaborative dialogues.

The second knowledge elicitation technique is interview. We also planned to interview the participants after the observation and expected to answer the research question 3 by collecting data about the human GIS operators' reasoning process underlying their collaborative communication with users during the observation process. We also expected to answer the question 2 about their different understandings of the same vague spatial concept in different communication contexts.

\section{Data Collection}

Four pairs of GIS expert operator participants and non-expert user participants participated in our study. They were all university staff or graduate students. All of them spoke in English fluently. This section details the entire knowledge elicitation data collection process. 


\subsection{Introduction Session}

After a pair of GIS expert operator participant and non-expert user participant came to our experiment location (a computer lab), we first distributed consent forms to them and collected the forms back when they were done with reading and signing the forms.

Consequently, to the user participant, we introduced basic concepts of GIS, such as its definition, major functions and applications. We also explained the eight tasks (Table 1) to be completed later with the GIS expert participant together. We required the user participant to keep the context specified for each task in mind and express each request as naturally as possible to the operator participant.

Finally, to the operator participant, we demonstrated major GIS functions, in particular, those that would be used to complete the required tasks. The demonstration was on a laptop to be used by the operator later to help the user participant. It was installed with GIS software, ArcView 3.1. We also required the operator participant to practice using the laptop and the GIS software, in particular, those major GIS functions.

\subsection{Observation Session}

The pair of participants started to work on the eight tasks together after the introduction session. The user participant read requirements for each of the eight tasks at first, and then talked to the operator participant for each request. The operator participant helped the user participant to generate a map for each task. They often had several round of collaborative dialogues for most of the tasks.

When the pair of participants collaborated with each other on these tasks, we recorded the entire collaboration process via a video camcorder. The researcher focused on observing and taking written notes on their collaborative dialogue strategies and major their facial expressions, in particular, when they stopped talking or working and were hesitating for something. Those collaborative dialogue strategies used and stopping would lead to questions and discussion in the later interview.

\subsection{Interview Session}

We interviewed the participants right after the observation session so that they would still remember what happened in the observation session and what they had thought in order to handle the vagueness problem. The interview process was recorded as digital audio data and written notes.

At first, we gave a short interview to the user participant. The participant was asked with questions about how they understood the meaning of the vague spatial concept near in the tasks 1 to 4 and how they did in the group of tasks $5-8$. We also asked the participant to list all possible collaborative dialogue strategies that he/she thought could help to handle the vagueness problem and order them.

We interviewed the operator participant consequently. In addition to the questions asked for the user participant, the questions to the operator participant focused on his/her reasoning process involved in handling the vagueness problem. We asked the reason why some collaborative dialogue strategies was used in some of the tasks and 
the participant's mental belief on the parameter that was instantiated by the vague spatial concept near and the execution result of GIS commands that used the parameter value instantiated from near. We also asked why they stopped working or hesitated for a while during the observation session if they did so.

\section{Findings}

The data that we collected all are qualitative. So, we take an interpretative reading method to read and analyze the data collected. This section summarizes the findings from our data analysis.

\subsection{Understanding of a Vague Spatial Concept}

The meaning of a vague spatial concept is understood in a context where the map is used. For example, the GIS operator participants understood the meaning of the vague spatial concept near in communication by imaging the situation that the requested map was used for. One operator participant showed a map of grocery stores that he thought were near to the user after receiving the request from the user. He explained how he estimated near during the operation in the interview. He was thinking how he was going to shop, such as driving a car from the specified apartment to those grocery stores. Then, he assumed that this was the user's reason to ask for the map.

\subsection{Collaborative Dialogue Strategies}

We find five major collaborative dialog strategies that the GIS operator can take to handle the vagueness problem:

- Strategy 1: The GIS operator shows a map result with a parameter value estimated from a vague spatial concept, and then asks the user for comments on the map result;

- Strategy 2: The operator directly tells the user an estimated meaning of the vague spatial concept by the operator and asks the user for feedback on the estimated meaning directly;

- Strategy 3: The GIS operator asks the user for some major contextual factors that influence the meaning of the vague spatial concept to have a better understanding of the concept;

- Strategy 4: The GIS operator directly asks the user for the meaning of the vague spatial concept that the user intends and then uses it in the GIS operation;

- Strategy 5: The GIS operator asks the user for modifying comments on an existing estimated meaning of a vague spatial concept.

\subsection{Reasoning Process}

When the GIS operator receives the request involving a vague spatial concept, he/she needs to make a decision about what to do next, e. g. taking one of the five collaborative dialogue strategies described above. The recognition-primed decision (RPD) 
model [28, 29] explains human's decision making process. To explain the GIS operator's decision-making process involved in handling the vagueness problem, we analyze our interview data and summarize major features of a computational RPD model that describes the GIS operator's decision making process. The results are given in Table 2.

Table 2. Major Features of a Computational RPD Model

\begin{tabular}{|c|c|c|c|c|}
\hline \multicolumn{2}{|c|}{$\begin{array}{l}\text { Key Cues } \\
\text { (to identify the problem) }\end{array}$} & \multirow[t]{2}{*}{ Goals } & \multirow[t]{2}{*}{ Expectancies } & \multirow{2}{*}{$\begin{array}{l}\text { Course } \\
\text { of } \\
\text { Actions }\end{array}$} \\
\hline Common & Different & & & \\
\hline \multirow{5}{*}{$\begin{array}{l}\text { The user } \\
\text { utterance is } \\
\text { clear; } \\
\text { There is a } \\
\text { GIS } \\
\text { command } \\
\text { available for } \\
\text { the request; } \\
\text { A spatial } \\
\text { concept } \\
\text { expressed in } \\
\text { the user's } \\
\text { utterance is } \\
\text { vague; } \\
\text { The user has } \\
\text { not provided } \\
\text { an exact } \\
\text { meaning of } \\
\text { the vague } \\
\text { concept. }\end{array}$} & \multirow{2}{*}{$\begin{array}{l}\text { Some contextual } \\
\text { information is provided } \\
\text { by the user or assumed } \\
\text { by the operator. The } \\
\text { operator has knowledge } \\
\text { about how to estimate a } \\
\text { meaning of the vague } \\
\text { spatial concept based on } \\
\text { context information. }\end{array}$} & \multirow[t]{5}{*}{$\begin{array}{l}\text { Instantiate } \\
\text { a para in } \\
\text { the GIS } \\
\text { command } \\
\text { from the } \\
\text { vague } \\
\text { concept }\end{array}$} & $\begin{array}{l}\text { The user is able to } \\
\text { provide comments on } \\
\text { the estimated } \\
\text { meaning of the vague } \\
\text { spatial concept } \\
\text { shown on the map }\end{array}$ & $\begin{array}{l}\text { Strategy } \\
1\end{array}$ \\
\hline & & & $\begin{array}{l}\text { The user is able to } \\
\text { provide comments on } \\
\text { the explicitly } \\
\text { expressed estimated } \\
\text { meaning of the vague } \\
\text { spatial concept. }\end{array}$ & $\begin{array}{l}\text { Strategy } \\
2\end{array}$ \\
\hline & $\begin{array}{l}\text { Part of major context } \\
\text { information has not been } \\
\text { shared by the user. }\end{array}$ & & $\begin{array}{l}\text { The user is able to } \\
\text { provide such context } \\
\text { information. }\end{array}$ & $\begin{array}{l}\text { Strategy } \\
3\end{array}$ \\
\hline & & & $\begin{array}{l}\text { The user is able to } \\
\text { provide an exact } \\
\text { meaning of the vague } \\
\text { spatial concept. }\end{array}$ & $\begin{array}{l}\text { Strategy } \\
4\end{array}$ \\
\hline & $\begin{array}{l}\text { An existing estimated } \\
\text { meaning of the vague } \\
\text { spatial concept has been } \\
\text { provided to the user. }\end{array}$ & & $\begin{array}{l}\text { The user is able to } \\
\text { provide modifying } \\
\text { comments on the } \\
\text { existing estimated } \\
\text { meaning of the vague } \\
\text { spatial concept. }\end{array}$ & $\begin{array}{l}\text { Strategy } \\
5\end{array}$ \\
\hline
\end{tabular}

\section{Conclusion}

This paper describes a knowledge elicitation study that we conducted to help a speech enabled GIS to handle the vagueness problem in human-GIS communication. The preliminary findings about how human communicators understand the meaning of a vague spatial concept in communication help us to better understand the vagueness problem in human-GIS communication and how the GIS can understand the meaning 
of a vague spatial concept in the communication context. The findings about various collaborative dialogue strategies and the human GIS operator's decision-making process help us to design intelligent speech enabled GIS which can handle the vagueness problem through collaborative dialogues. These findings are also useful for design of other speech enabled information systems to handle vagueness in humancomputer communication.

Acknowledgments. This material is based upon work supported by the National Science Foundation under Grants No. BCS-0113030, and EIA-0306845. This work is also supported by Northern Kentucky University Faculty Summer Fellowship and Northern Kentucky University Faculty Project Grant. The author would like to thank Dr. Guoray Cai, Dr. Alan MacEachren and Dr. Michael McNeese for their advising to her work during her stay at Pennsylvania State University.

\section{References}

1. Chang, K.-t.: Introduction to Geographic Information Systems. McGraw-Hill, New York (2010)

2. Frank, A.U., Mark, D.M.: Language issues for GIS. In: Macguire, D., Goodchild, M.F., Rhind, D. (eds.) Geographical Information Systems: Principles and Applications, pp. 147163. Wiley, New York (1991)

3. Mark, D.M., Svorou, S., Zubin, D.: Spatial terms and spatial concepts: Geographic, cognitive, and linguistic perspectives. In: Proceedings of International Geographic Information Systems (IGIS) Symposium: The Research Adgenda, vol. 2, pp. 101-112 (1987)

4. Florence, J., Hornsby, K., Egenhofer, M.J.: The GIS Wallboard: interactions with spatial information on large-scale display. In: Kraak, M.-J., Molenaar, M. (eds.) Seventh International Symposium on Spatial Data Handling (SDH 1996), pp. 8A. 1-15 (1996)

5. Mark, D.M., Frank, A.U.: NCGIA Initiative 2, "Languages of Spatial Relations". Closing Report.: National Center for Geographic Information and Analysis, Santa Barbara, CA (1992)

6. Mark, D.M., Frank, A.U.: User interfaces for Geographic Information Systems: report on the specialist meeting. National Center for Geographic Information and Analysis (1992)

7. Bolt, R.A.: Put-that-there: voice and gesture at the graphics interface. In: Proceedings of the 7th Annual Conference on Computer Graphics and Interactive Techniques, pp. 262-270 (1980)

8. Neal, J.G., Thielman, C.Y., Funke, D.J., Byoun, J.S.: Multi-modal output composition for human-computer dialogues. In: Antonisse, H.J., Benoit, J.W., Silverman, B.G. (eds.) Proceedings of the 1989 AI Systems in Government Conference, pp. 250-257 (1989)

9. Cohen, P., Dalrymple, M., Moran, D., Pereira, F.: Synergistic use of direct manipulation and natural language. In: CHI 1989, pp. 227-234. ACM/Addison Wesley (1989)

10. Oviatt, S.L.: Pen/voice: Complementary multimodal communication. In: Proceeding of Speech Technology 1992, pp. 238-241 (1992)

11. Oviatt, S.L.: Multimodal interfaces for dynamic interactive maps. In: Proceedings of the Conference on Human Factors in Computing Systems (CHI 1996), pp. 95-102 (1996)

12. Egenhofer, M.J.: Multi-modal spatial querying. In: Kraak, J.M., Molenaar, M. (eds.) Advances in GIS Research II (Proceedings of The Seventh International Symposium on Spatial Data Handling), pp. 785-799. Taylor \& Francis, London (1996) 
13. Sharma, R., Yeasin, M., Krahnstoever, N., Rauchert, I., Cai, G., Brewer, I., MacEachren, A.M., Sengupta, K.: Speech-gesture driven multimodal interfaces for crisis management. Proceedings of the IEEE 91, 1327-1354 (2003)

14. MacEachren, A.M., Cai, G., Sharma, R., Rauschert, I., Brewer, I., Bolelli, L., Shaparenko, B., Fuhrmann, S., Wang, H.: Enabling Collaborative GeoInformation Access and DecisionMaking Through a Natural, Multimodal Interface. International Journal of Geographical Information Science 19, 293-317 (2005)

15. Wang, F.: Handling Grammatical Errors, Ambiguity and Impreciseness in GIS Natural Language Queries. Transactions in GIS 7, 103-121 (2003)

16. Bosc, P., Prade, H.: An introduction to fuzzy set and possibility theory based approaches to the treatment of uncertainty and imprecision in database management systems. In: Proceedings of the 2nd Workshop on Uncertainty Management in Information Systems: From Needs to Solutions (1993)

17. Owei, V.: An intelligent approach to handling imperfect information in concept-based natural language queries. ACM Transactions on Information Systems 20, 291-328 (2002)

18. Robinson, V.B., Thongs, D., Blaze, M.: Machine acquisition and representation of natural langauge concepts for geographic information retrieval. In: Proceedings of 16th Annual Pittsburgh Conference, vol. 1, pp. 161-166 (1985)

19. Cooke, N.J.: Varieties of knowledge elicitation techniques. International Journal of HumanComputer Studies 41, 801-849 (1994)

20. Boose, J.H., Bradshaw, J.M.: Expertise transfer and complex problems: using Aquinas as a knowledge-acquisition workbench for knolwedge-based systems. International Journal of Man-Machine Studies 26, 3-28 (1987)

21. Cordingley, E.S.: Knowledge elicitation techniques for knowledge-based systems. In: Diaper, D. (ed.) Knowledge Elicitation: Principles, Techniques and Applications. Ellis Horwood Ltd., Chichester (1989)

22. Meyer, M.A., Paton, R.C.: Towards an analysis and classification of approaches to knowledge acquisition from examination of textual metaphor. Knowledge Acquisition 4, 347-369 (1992)

23. Olson, J.R., Biolsi, K.J.: Techniques for representing expert knowledge. In: Ericsson, K.A., Smith, J. (eds.) Toward a General Theory of expertise, pp. 240-285. Cambridge University Press, Cambirdge (1991)

24. Wang, F.: Towards a natural language user interface: An approach of fuzzy query. International Journal of Geographical Information Systems 8, 143-162 (1994)

25. Wang, F.: A fuzzy grammar and possibility theory-based natural language user interface for spatial queries. Fuzzy Sets and Systems 113, 147-159 (2000)

26. Yao, X., Thill, J.-C.: How Far Is Too Far? A Statistical Approach to Context-contingent Proximity Modeling. Transactions in GIS 9, 157-178 (2005)

27. Yao, X., Thill, J.-C.: Spatial queries with qualitative locations in spatial information systems. Computers, Environment and Urban Systems 30, 485-502 (2006)

28. Klein, G.A.: Recognition-primed decisions. In: Rouse, W.B. (ed.) Advances in ManMachine Systems Research, pp. 47-92. JAI Press, Greenwich (1989)

29. Klein, G.A.: Recognition-Primed Decision Making. In: Klein, G.A. (ed.) How People Make Decisions, pp. 15-30. MIT Press, Cambridge (1998) 